\title{
BMJ Open Individualised targets for insulin initiation in type 2 diabetes mellitus - the influence of physician and practice: a cross-sectional study in eight European countries
}

To cite: Boels AM, Koning E, Vos RC, et al. Individualised targets for insulin initiation in type 2 diabetes mellitus-the influence of physician and practice: a cross-sectional study in eight European countries. BMJ Open 2019;9:e032040. doi:10.1136/ bmjopen-2019-032040

- Prepublication history and additional material for this paper are available online. To view these files, please visit the journal online (http://dx.doi. org/10.1136/bmjopen-2019032040).

AMB and EK are joint first authors.

Received 09 July 2019 Revised 11 July 2019 Accepted 12 July 2019

Check for updates

(c) Author(s) (or their employer(s)) 2019. Re-use permitted under CC BY-NC. No commercial re-use. See rights and permissions. Published by BMJ.

For numbered affiliations see end of article.

Correspondence to Ms Anne Meike Boels; a.m.boels-2@umcutrecht.nl

\section{ABSTRACT}

Objectives To determine at what glycated haemoglobin (HbA1c) level physicians from eight European countries would initiate insulin in type 2 diabetes, which physician or practice related factors influenced this level and whether physicians would differentiate between a younger uncomplicated patient and an older patient with comorbidities.

Design Cross-sectional study with data from the Guideline Adherence to Enhance Care study.

Setting and participants 410 physicians from both primary and secondary care from Belgium, France, Germany, Italy, Ireland, Sweden, the Netherlands and the UK.

Outcome measures Physicians were asked at which $\mathrm{HbA1c}$ level they would initiate insulin for a young, uncomplicated patient (vignette 1) and for an older, complicated patient (vignette 2). We evaluated differences in HbA1c levels between physicians from different countries using analysis of variance. To identify physician and practice related factors associated with $\mathrm{HbA} 1 \mathrm{c}$ level at initiation of insulin, we performed multivariable linear regression. Multiple imputation was used to deal with missing data.

Results In Germany, Ireland, Sweden, the Netherlands and the UK, the $\mathrm{HbA1c}$ levels for initiating insulin in vignette 2 (range: 60.0 to $66.0 \mathrm{mmol} / \mathrm{mol} ; 7.6 \%$ to $8.2 \%$ ) were higher than for vignette 1 (range: 57.2 to $64.2 \mathrm{mmol} /$ mol; $7.4 \%$ to $8.0 \%$ ). In multivariable analysis, the $\mathrm{HbA} 1 \mathrm{C}$ level at which insulin was initiated only differed between countries (vignette 1): Dutch physicians initiated insulin at a lower HbA1c level compared with Belgium, France and the UK. No physician or practice factors were independently associated with $\mathrm{HbA1c}$ level at insulin initiation.

Conclusions When deciding on individualised $\mathrm{HbA1C}$ targets for insulin initiation, physicians from five countries took patient's age and comorbidity into account. The $\mathrm{HbA1c}$ level at which physicians would initiate insulin therapy differed between countries.

\section{INTRODUCTION}

Due to the progressive nature of type 2 diabetes mellitus (T2DM), it is often
Strengths and limitations of this study

- This study is novel; only two previous studies have investigated physician related factors for individualised insulin initiation in type 2 diabetes.

- Including physicians from eight European countries reveals the diversity in treatment decisions across Europe.

- The use of vignettes provides a 'clean' view on physician's opinions, but vignettes cannot be directly linked to physician behaviour in practice.

- Physicians participating in this study might have more interest with type 2 diabetes, which could influence the generalisability.

necessary to initiate insulin treatment, a drug well known for its efficacy. ${ }^{2-4}$ Insulin therapy is however complex. Due to this complexity, the initiation of insulin is often delayed or postponed, resulting in high glycated haemoglobin (HbA1c) levels at the time of insulin initiation. ${ }^{5-9}$ This issue of therapeutic inertia has not changed over the last 10 years. ${ }^{10} 11$ Formally, it has been described as 'the failure of healthcare providers to initiate or intensify therapy when indicated', ${ }^{12}$ but recently, a new definition of therapeutic inertia has been proposed: 'failure to advance therapy or to de-intensify therapy when appropriate to do so'. ${ }^{13}$ Factors associated with therapeutic inertia have been categorised as originating from the healthcare system, the patient and the physician. ${ }^{14}$

Factors in the healthcare system responsible for postponing insulin therapy are limited resources, discontinuity of care, lack of time and a lack of financial incentives. ${ }^{1516}$ Furthermore, glycaemic targets differ between countries. For example: in the UK the glycaemic target is 48 to $53 \mathrm{mmol} / \mathrm{mol}(6.5 \%$ to $7 \%)$, 
while physicians in Sweden should strive for an HbAlc between 42 to $69 \mathrm{mmol} / \mathrm{mol}(6 \%$ to $8.5 \%) .{ }^{17}{ }^{18}$ In choice of treatment, differences between countries are also apparent: the Guideline Adherence to Enhance Care (GUIDANCE) study showed that in France only 16.7\% of T2DM patients use insulin, compared with $38.0 \%$ in Germany. ${ }^{19}$

Several patient related factors influence the HbA1c level at which insulin is initiated. Because of differential benefits from strict glycaemic control, the European Association for the Study of Diabetes (EASD) and the American Diabetes Association (ADA) proposed individualising the glycaemic target.$^{20}$ For younger people with T2DM a strict glycaemic target is desirable, for it is proven to be beneficial on long-term health outcomes. ${ }^{3}$ Elderly people, those with a longer diabetes duration and those with comorbidities or complications, are likely to have less benefit from intensive treatment, thus a less stringent glycaemic target may be preferable $;{ }^{21-23}$ but patients themselves can also be reluctant to start insulin therapy. Approximately $25 \%$ to $33 \%$ of patients even expresses unwillingness to start insulin at all, ${ }^{24} 25$ mainly because of needle anxiety, fear of weight gain, fear of hypoglycaemia and feelings of failure. ${ }^{2627}$

Nevertheless, physicians are the most important cause of therapeutic inertia in general, contributing $50 \%$ to $75 \%$ of all three factors. ${ }^{1428}$ The physicians' contribution is a global phenomenon. ${ }^{8} 929$ Physicians postpone initiating insulin therapy for several reasons, including concerns about non-adherence, doubts about patient competence, fear of hypoglycaemia and lack of knowledge or experience. ${ }^{24} 2530$ Therapeutic inertia is seen in both primary and specialist care, but seems more pronounced in primary care. $^{31}$

Almost all studies on therapeutic inertia in T2DM have focused on healthcare system or patient factors associated with delayed insulin initiation, studies aimed at physician factors are scarce and non-conclusive. ${ }^{32}{ }^{33} \mathrm{~A}$ study in secondary care physicians showed that older doctors, female doctors and those seeing more patients per month had an increased delay in initiating insulin. ${ }^{33}$ However, many factors such as the usage of guidelines, physicians' opinions on guidelines and the influence of HbA1c targets in national guidelines, remain unexplored.

We investigated if there is any variation between physicians from eight European countries at which HbAlc level they initiate insulin treatment, and whether these HbA1c levels differ for younger T2DM patients without comorbidities versus older T2DM patients with comorbidities. We also investigated which physician and practice related factors are associated with the HbAlc level at which insulin treatment is initiated.

\section{METHODS}

\section{Study design}

For this study we used data from the GUIDANCE study, a cross-sectional study conducted in Belgium, France,
Germany, Italy, Ireland, Sweden, the Netherlands and the UK to determine the quality of T2DM care. ${ }^{19}$ Data were collected concurrently in all participating countries from March 2009 to December 2010. Further details of the methods have been described previously. ${ }^{19}$

\section{Study population}

In each country, a coordinating researcher recruited physicians. Physicians were recruited primarily from primary care and in case of insufficient numbers of primary care physicians from specialist care. The coordinating researchers aimed to include a representative sample of caregivers for T2DM in a given country, but were allowed a certain flexibility in this matter. For example, in the Netherlands about $90 \%$ of people with T2DM are treated in primary care and hence all participating physicians were recruited from the primary care setting physicians could be working either independently (solo practice) or in group practices/centres. Physicians were eligible if they had any level of involvement in the care of individuals with T2DM. All physicians gave permission to use the collected data.

\section{Patient and public involvement}

Patients and public were not involved in the design of the current study.

\section{Data collection}

The database of the GUIDANCE study consists of both patient and physician data. In this study, we focused on data from physician questionnaires.

Physicians filled out a questionnaire, consisting of three parts. The first part contained general questions about characteristics of the physician, such as age and information on the practice setting, the number of patients in general and those with T2DM seen per week. It also contained questions concerning practice characteristics: services available to the practice and patient education content, education resources and the form of education. We considered the presence of a diabetes educator or a nurse available if either or both were present in the care centre.

The second part included questions on diabetes management. Physicians were asked at what HbAlc level they would initiate insulin treatment in two different vignettes:

- At what HbAlc level do you usually initiate insulin treatment in a 50-year-old patient without serious diseases?

- At what HbAlc level do you usually initiate insulin treatment in an 80-year-old patient with myocardial infarction?

These questions create two cases: one with a young individual without comorbidities (vignette 1 ), and one with an older individual with a comorbidity (vignette 2).

The last part of the physician questionnaire inquired whether physicians used guidelines, and if so, which one (s), and what target HbA1c these guidelines recommended 
according to the physician. Moreover, a separate set of 17 questions to determine physician's attitude towards the guidelines was completed. The 17 questions were on a 5-point Likert scale ranging from 1 "strongly disagree" to 5 "strongly agree", with a total score ranging from 17 to 85 , a higher score indicating a more positive feeling towards the guidelines. These questions were specifically designed for the purpose of the GUIDANCE study and were not part of a validated questionnaire.

Additionally we extracted glycaemic targets from a previous study and national (primary care) guidelines for all countries ${ }^{34}$; both from the guidelines valid in 2009 during the GUIDANCE study and from the most recent guidelines.

\section{Sub-study}

Since the GUIDANCE data were already a couple of years old and the most recent guidelines now all propose individualised $\mathrm{HbA} 1 \mathrm{c}$ targets (see table 1), we wanted to assess whether this might have influenced physicians' behaviour. Therefore, we repeated the GUIDANCE survey among Dutch primary care physicians in 2018. We contacted all Dutch physicians who participated in the original GUIDANCE study. Unfortunately many physicians were retired; we therefore also sent the survey to all "new" physicians working at the participating primary care practices. Since our aim was only to get a feeling about any time trend, we only repeated the survey in Dutch physicians. Moreover, we did not have the financial and logistical resources to repeat the study in all eight countries.

\section{Statistical analyses}

Because missing data will lead to imprecision and may lead to bias, multiple imputation was used to deal with missing data. Characteristics of physicians with any missing value and those with complete data are shown in online supplementary appendix 1, suggesting data are missing at random. We created 10 imputed data sets under the assumption 'missing at random'. We used the formula ' $(10.93 \times \mathrm{HbA1c}$ in \%) - 23.50' to convert National Glycohemoglobin Standardization Program (NGSP) HbA1c (\%) to International Federation of Clinical Chemistry (IFCC) HbAlc $(\mathrm{mmol} / \mathrm{mol})$; for Sweden we used ' $(10.11 \times \mathrm{HbA} 1 \mathrm{c}$ in \% $)-8.94$ ' to convert the nationally used Mono-S HbA1c (\%) to IFCC HbA1c $(\mathrm{mmol} / \mathrm{mol})$.

One-way analysis of variance was used to compare the HbA1c levels between physicians from the eight countries for both vignette 1 and 2, post-hoc analysis was done using Tukey's test. Additionally, we calculated the difference in HbA1c level between vignette 1 and 2 per country, by subtracting the HbAlc from vignette 1 from vignette 2 per physician. To test whether the HbAlc levels differed significantly between vignette 1 and 2 per country, we performed paired t-tests.

To investigate which factors were associated with the HbAlc level at which insulin treatment was initiated, we included the following determinants based on literature ${ }^{32} 3^{3}$ : physician's age, country, primary versus secondary care setting and the presence of a diabetes educator or nurse in the care centre. Based on expert opinion, we also added the following determinants: whether the physician uses T2DM guidelines (yes/no), physician's attitude towards guidelines (score range 17 to 85), HbA1c in guideline according to physician, whether the physicians provides education to T2DM patients themselves (yes/no), absolute number of patients per week and relative number of T2DM patients per week (the number of patients with T2DM seen per week divided by the total number of patients seen per week). First, all variables except for country were investigated in a univariable linear regression (model 1), second in a multivariable linear regression (model 2) and finally country was added to the multivariable model (model 3). Country was added last since we wanted the emphasise its role.

Since one could argue that the data have a two-level hierarchical structure (physicians working within a country), we conducted a sensitivity analysis by adding random intercepts per country to model 2 (ie, a linear mixed model).

Analyses were performed using IBM SPSS Statistics V.21 for Windows. Assumptions for all statistical tests were checked. $P$ values $<0.05$ were considered statistically significant.

\section{RESULTS}

Of the 429 physicians, 19 physicians were excluded since they indicated not to initiate insulin at all (Ireland: $n=14$, France: $\mathrm{n}=1$, UK: $\mathrm{n}=4$ ). Before imputation, $4.9 \%$ of data was missing, distributed among $28.2 \%$ of the cases. Assumptions for all statistical tests were satisfied.

Table 1 shows the country and physician characteristics (complete cases). The number of participating physicians per country varied from 20 in Italy to 78 in France. The majority of physicians worked in primary care, except in Italy and Ireland $(50.0 \%$ and $25.9 \%$, respectively). German physicians saw the largest number of patients with a median of 275 . In contrast, their colleagues from Sweden saw a median of 50 patients per week. Physicians from other countries saw approximately 100 patients per week. The highest percentage of patients with T2DM seen per week was reported by physicians from Italy (33.3\%) and Ireland (55.0\%). The target HbA1c in guideline according to the physician varied from $48.5 \mathrm{mmol} / \mathrm{mol}$ $(6.6 \%)$ in Germany to $52.2 \mathrm{mmol} / \mathrm{mol}(6.9 \%)$ in the Netherlands. Target HbA1c levels in national guidelines valid in 2009 (at the time of data collection) varied from $\leq 48 \mathrm{mmol} / \mathrm{mol}(\leq 6.5 \%)$ in France, Germany, Ireland and Sweden to $<53 \mathrm{mmol} / \mathrm{mol}(<7 \%)$ in Belgium and the Netherlands. Currently, all national guidelines propose a personalised target HbAlc.

In the 50-year-old patient without comorbidities (vignette 1), the HbA1c level at which physicians would initiate insulin treatment varied statistically significantly between countries $(\mathrm{p}<0.001)$; the lowest HbAlc level was reported by Dutch physicians $(57.2 \mathrm{mmol} / \mathrm{mol} ; 7.4 \%)$, 
Table 1 Country and physician characteristics, values are reported as means with SD, unless otherwise stated (complete case data)

\begin{tabular}{|c|c|c|c|c|c|c|c|c|}
\hline & Belgium & France & Germany & Ireland & Italy & NL & Sweden & UK \\
\hline $\begin{array}{l}\text { Number of } \\
\text { physicians }\end{array}$ & 73 & 78 & 38 & 27 & 20 & 58 & 62 & 54 \\
\hline Age (years) & $53.2(12.0)$ & $51.2(8.7)$ & $50.4(9.1)$ & $49.5(8.5)$ & $53.4(5.3)$ & 49.7 (7.9) & $53.6(9.2)$ & $47.1(8.6)$ \\
\hline $\begin{array}{l}\text { Percentage } \\
\text { primary care }\end{array}$ & $97.3 \%$ & $89.7 \%$ & $92.1 \%$ & $25.9 \%$ & $50.0 \%$ & $100 \%$ & $100 \%$ & $77.8 \%$ \\
\hline $\begin{array}{l}\text { Number of } \\
\text { patients per } \\
\text { week (median, } \\
\text { IQR) }\end{array}$ & $100(58)$ & $120(49)$ & 275 (150) & $90(100)$ & $100(70)$ & $112.5(59)$ & $50(22)$ & $120(80)$ \\
\hline $\begin{array}{l}\text { Percentage } \\
\text { T2DM of } \\
\text { patients per } \\
\text { week (median, } \\
\text { IQR) }\end{array}$ & $6.7(9.5)$ & $6.3(6.1)$ & $17.5(20.7)$ & $55.0(57.9)$ & $33.3(59.2)$ & $6.2(6.0)$ & $7.2(5.1)$ & $16.2(26.8)$ \\
\hline $\begin{array}{l}\text { Percentage } \\
\text { of physicians } \\
\text { suggesting } \\
\text { patients to } \\
\text { follow diabetes } \\
\text { education (yes/ } \\
\text { no) }\end{array}$ & $74.0 \%$ & $75.3 \%$ & $42.1 \%$ & $96.3 \%$ & $50.0 \%$ & $96.6 \%$ & $95.2 \%$ & $100 \%$ \\
\hline $\begin{array}{l}\text { Percentage } \\
\text { physicians } \\
\text { aware of T2DM } \\
\text { guidelines (yes/ } \\
\text { no) }\end{array}$ & $84.7 \%$ & $93.4 \%$ & $83.8 \%$ & $96.3 \%$ & $95.0 \%$ & $98.3 \%$ & $95.2 \%$ & $100 \%$ \\
\hline $\begin{array}{l}\text { Attitude } \\
\text { towards T2DM } \\
\text { guidelines } \\
\text { score (17-85) }\end{array}$ & $62(11)$ & $64(9)$ & $56(10)$ & $66(9)$ & $67(8)$ & $69(6)$ & $65(9)$ & $63(6)$ \\
\hline $\begin{array}{l}\text { Target } \mathrm{HbA} 1 \mathrm{c} \\
\text { in guideline } \\
\text { according } \\
\text { to physician } \\
\text { (mmol/mol) }\end{array}$ & $50.5(4.2)$ & 48.6 (3.3) & 48.5 (3.3) & $49.8(3.2)$ & 51.7 (1.9) & $52.2(3.0)$ & $49.4(4.1)$ & $51.1(2.8)$ \\
\hline $\begin{array}{l}\text { Target } \mathrm{HbA1c} \\
\text { in national } \\
\text { guidelines valid } \\
\text { in } \underline{2009}(\mathrm{mmol} / \\
\mathrm{mol})^{\star}\end{array}$ & $<53$ & $<48$ & $\leq 48$ & $<48$ & $48-53$ & $<53$ & $<48$ & $<48 \dagger$ \\
\hline $\begin{array}{l}\text { Target } \mathrm{HbA1c} \\
\text { in most recent } \\
\text { national } \\
\text { guidelines } \\
(\mathrm{mmol} / \mathrm{mol}) \ddagger\end{array}$ & $48-64$ & $48-75$ & $48-58$ & $48-58$ & $48-64$ & $53-64$ & $42-69$ & $48-53$ \\
\hline
\end{tabular}

${ }^{*}$ Glycaemic targets were extracted from reference. ${ }^{34}$

†Higher for individual patients.

$\ddagger$ Glycaemic targets were extracted from national guidelines from primary care for each country.

HbA1c, glycated haemoglobin; NL, the Netherlands; T2DM, type 2 diabetes mellitus; UK, United Kingdom.

the highest by Belgian physicians $(64.2 \mathrm{mmol} / \mathrm{mol} ; 8 \%)$, see figure 1 and table 2. Post-hoc analyses showed that Dutch physicians differed significantly in the HbA1c level at which they would initiate insulin therapy from their colleagues in France $(\mathrm{p}=0.021)$ and Belgium $(\mathrm{p}<0.001)$, and that Swedish physicians differed from those in Belgium $(p=0.017)$ (data not shown in Figure/Table).

In the 80-year-old patient with comorbidities (vignette 2), the HbAlc level at which physicians would initiate insulin treatment was not significantly different between 
$\mathrm{HbAlc}<58 \mathrm{mmol} / \mathrm{mol}(7-7.5 \%)$

$\mathrm{HbA} 1 \mathrm{C} 58-64 \mathrm{mmol} / \mathrm{mol}(7.5-8 \%)$

$\mathrm{HbA} 1 \mathrm{C}>64 \mathrm{mmol} / \mathrm{mol}(>8 \%)$

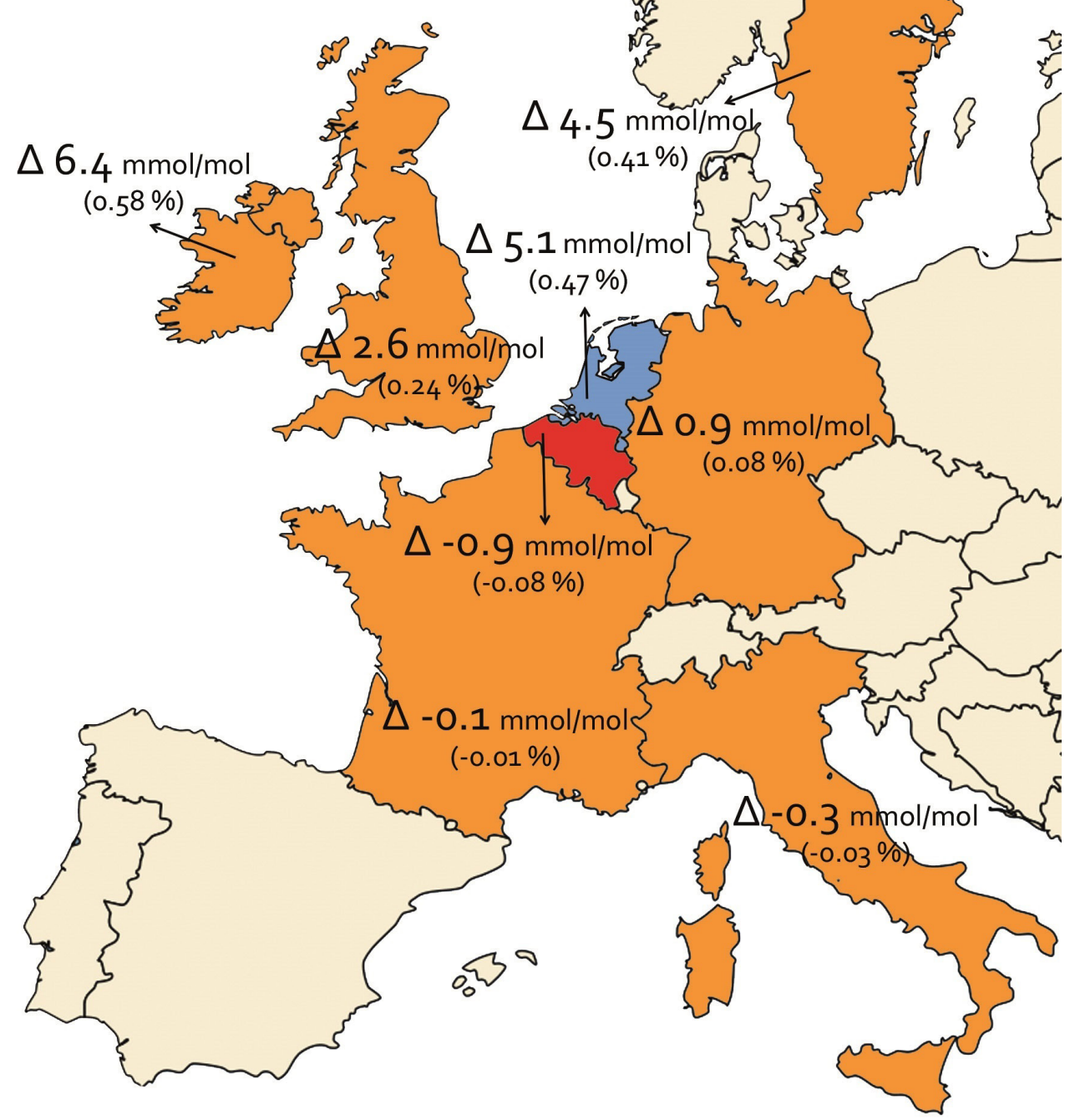

Figure 1 The mean $\mathrm{HbA1c}$ level to initiate insulin treatment in a 50-year-old patient without comorbidities (vignette 1). $\Delta$ (delta) represents the difference in $\mathrm{HbA1c}$ level between vignette 1 and vignette 2 (ie, the $\mathrm{HbA} 1 \mathrm{c}$ level in vignette 2 minus the $\mathrm{HbA} 1 \mathrm{c}$ level in vignette 1). HbA1c,glycated haemoglobin.

countries $(\mathrm{p}=0.401)$. Italian physicians reported the lowest HbAlc level at which they would initiate insulin $(60.0 \mathrm{mmol} / \mathrm{mol} ; 7.6 \%)$ while physicians in Ireland reported the highest $(66.0 \mathrm{mmol} / \mathrm{mol} ; 8.2 \%)$, see figure 1 and table 2.

Physicians from Belgium, France and Italy would initiate insulin at a slightly lower HbAlc level in vignette 2 (the older patient with comorbidities) compared with vignette 1 , see figure 1 and table 2 . On the contrary, physicians from Germany, Ireland, the Netherlands, Sweden and the UK would initiate insulin at a higher HbAlc level in vignette 2 (the older patient with comorbidities) compared with vignette 1 , with statistically significant differences between the two levels in Ireland $(\Delta$ $6.4 \mathrm{mmol} / \mathrm{mol} ; 0.58 \%)$, the Netherlands $(\Delta 5.1 \mathrm{mmol} /$ mol; $0.47 \%)$, Sweden $(\Delta 4.5 \mathrm{mmol} / \mathrm{mol} ; 0.41 \%)$ and the UK $(\Delta 2.6 \mathrm{mmol} / \mathrm{mol} ; 0.24 \%)$, see figure 1 and table 2 .

Online supplementary appendix 2 shows the results of the sub-study. In total 58 physicians responded to the survey, of which 33 participated in the original GUIDANCE study. In the 50-year-old patient without comorbidities (vignette 1), the HbAlc level at which Dutch physicians would initiate insulin treatment in 2018 was $56.5 \mathrm{mmol} / \mathrm{mol}(7.3 \%)$ for the participants from the original GUIDANCE study and $55.4 \mathrm{mmol} / \mathrm{mol}(7.2 \%)$ for the new participants, see online supplementary appendix 2. In 2009 , this $\mathrm{HbAlc}$ level was $57.2 \mathrm{mmol} / \mathrm{mol}(7.4 \%)$, see table 2. For vignette 2, the HbA1c level at which Dutch physicians would initiate insulin in 2018 was $62.8 \mathrm{mmol} /$ mol $(7.9 \%)$ for the participants from the original 


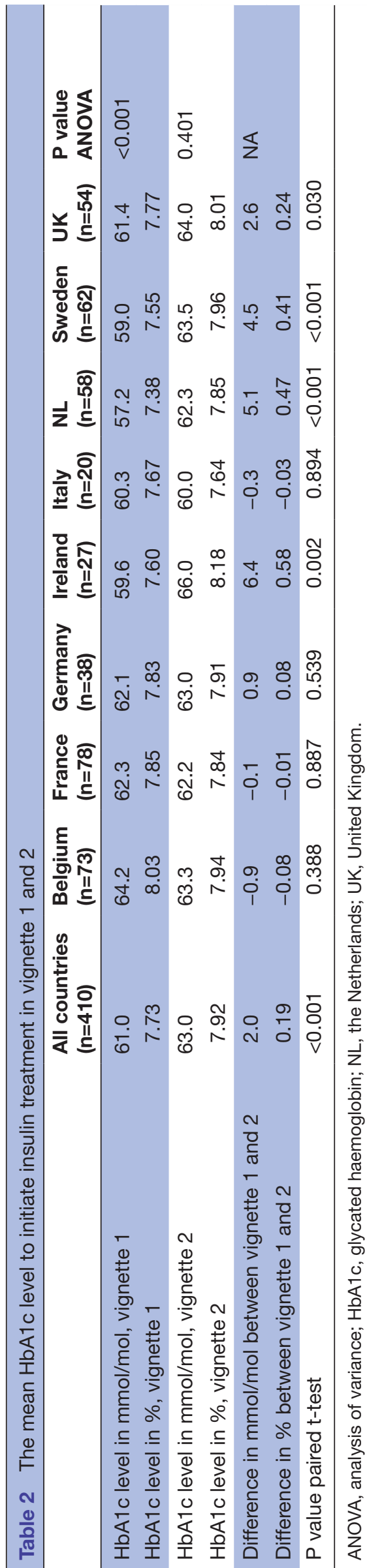

GUIDANCE study and $61.7 \mathrm{mmol} / \mathrm{mol}(7.8 \%)$ for the new participants, see online supplementary appendix 2 .

In 2009, this $\mathrm{HbAlc}$ level was $62.3 \mathrm{mmol} / \mathrm{mol}(7.9 \%)$, see table 2 .

Table 3 shows which factors were associated with the HbA1c level at which insulin would be initiated in vignette 1. In the univariable analysis (model 1 ), we found a statistically significant association between physicians' attitude towards guidelines and HbAlc level at which insulin will be initiated: for every additional positive point on a 17 to 85 scale, physicians would initiate insulin at a $0.14 \mathrm{mmol} /$ mol lower HbA1c level. In other words: a more positive attitude towards the guidelines was associated with a lower HbA1c level at which insulin will be initiated. There were no statistically significant associations between the HbA1c level at which insulin would be initiated and physician's age, setting, number and percentage T2DM patients, target HbA1c in guidelines, guideline unawareness, attitude towards guidelines, education given by physicians and the presence of a nurse or diabetes educator in the care centre.

In the first multivariable analysis (model 2), the association between physicians' attitude towards guidelines and HbAlc level at which insulin will be initiated remained significant. However, when country was added to the multivariable model (model 3, reference category: the Netherlands), these results were nullified; only differences in HbA1c level at which insulin was initiated between Dutch physicians and those from Belgium, France and the UK were significant. There were no associations between the HbAlc level at which insulin will be initiated and all other variables, for example physician's age, practice setting, the target HbAlc in the guideline according to the physician, education by the physician or the presence of a nurse or diabetes educator. The sensitivity analysis yielded similar results (see online supplementary appendix 3 ).

Table 4 shows which factors were associated with the HbA1c level at which insulin would be initiated in vignette 2. In the univariable analyses and in both multivariable analyses, there were no significant associations. The sensitivity analysis could not be performed for vignette 2. Because the HbAlc levels at which insulin was initiated in vignette 2 were more similar between countries, there was too limited variance to allow random intercepts in the model, hence the model could not converge.

\section{DISCUSSION}

\section{Summary of findings}

Physicians from eight European countries would initiate insulin at different HbAlc levels in the younger patient without comorbidities, but not in the older patient with comorbidities. Although the HbA1c levels varied between the countries and different vignettes, physicians from all countries reported to initiate insulin above $53 \mathrm{mmol} / \mathrm{mol}$ (7\%) for both vignettes. In five out of eight countries, physicians stated that they would start insulin at a higher HbA1c level in the older, complicated patient. The only 


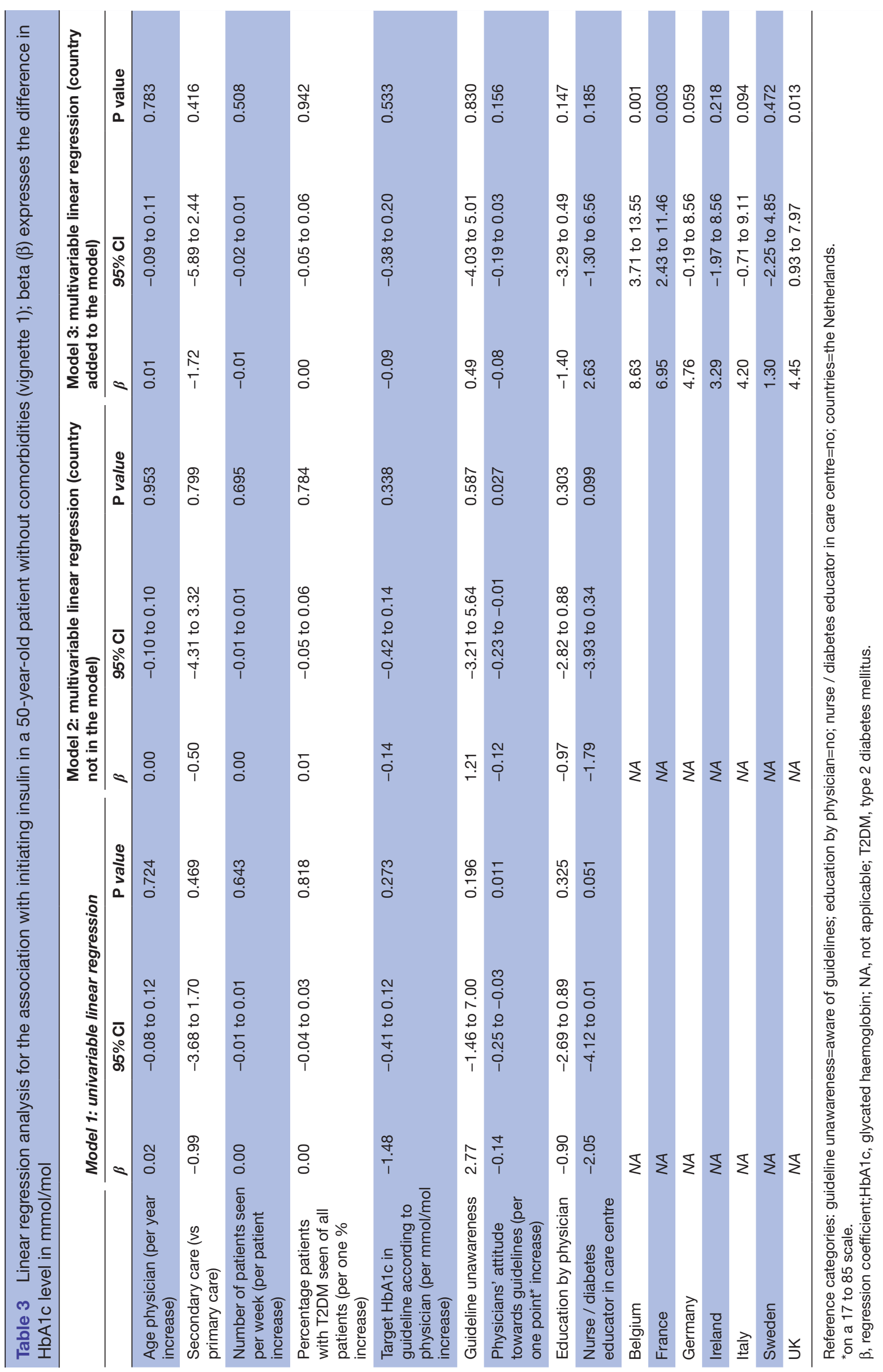


Table 4 Linear regression analysis for the association with initiating insulin in an 80-year-old patient with comorbidities (vignette 2); beta ( $\beta$ ) expresses the difference in $\mathrm{HbA} 1 \mathrm{c}$ level in $\mathrm{mmol} / \mathrm{mol}$

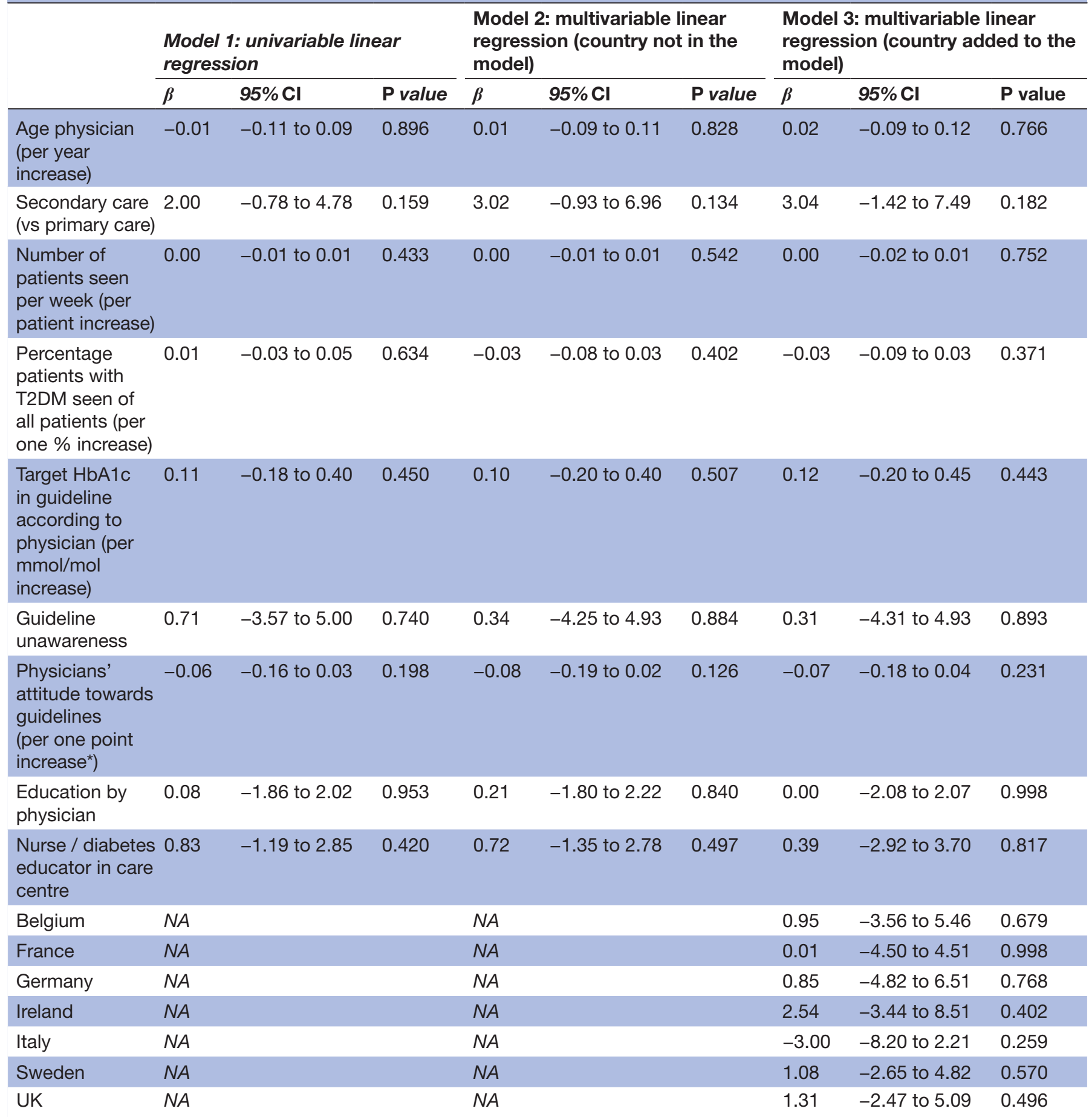

Reference categories: guideline unawareness=aware of guidelines; education by physician=no; nurse / diabetes educator in care centre=no. *on a 17 to 85 scale.

$\beta$, regression coefficient; HbA1c, glycated haemoglobin; NA, not applicable; T2DM, type 2 diabetes mellitus.

factor associated with the HbA1c level to initiate insulin therapy in the younger patient without comorbidities was the physician's attitude towards national diabetes guidelines. However, when adding country as a factor only the difference between the Netherlands and Belgium, France and the UK remained statistically significant;Dutch physicians initiated insulin at a lower HbAlc level.

\section{Strengths and limitations}

Only two previous studies have investigated physician related factors for insulin initiation in type 2 diabetes. By including physicians from eight European countries, we were able to show the diversity in treatment decisions across Europe, which can be considered a strength of the study. Because of the limited number of physicians per 
country, we were not able to investigate within country differences. We measured the intention of the physicians without additional complexities such as patient preferences. Such a vignette cannot directly be linked to their behaviour in practice. Individual patient factors and perceptions will inevitably influence the decision to initiate insulin. Another limitation is that physicians participating in this study might be more familiar and have more interest in the management of people with T2DM; as a consequence results may not be entirely generalisable to all physicians. National coordinating researchers aimed to include a representative sample of caregivers for T2DM in a given country. Nevertheless, they were allowed a certain flexibility in this matter and hence the representativeness of the sample is mainly based on expert opinion of these national coordinating researchers. For example, while in the Netherlands the majority of people with T2DM is treated in primary care, approximately $10 \%$ is treated in secondary care. No secondary care doctors were included in the Dutch sample, and therefore results may not be fully generalisable. A formal search into the generalisability of the different study samples per country has not been performed. However, participating in the GUIDANCE study involved a low level of commitment and therefore we assume that the participating physicians were not only those with a particular interest in diabetes. Furthermore, the questionnaire to determine the physicians' attitude towards the national guideline was not validated. While physicians' sex was previously demonstrated to be associated with insulin delay, ${ }^{33}$ we were unfortunately unable to investigate this association because data on physicians' sex was not included in our database. Lastly, data were collected 8 to 9 years prior to the conduct of the current analysis. We repeated the GUIDANCE survey among Dutch physicians and the results of this survey suggest that physicians in 2018 would initiate insulin at approximately the same HbAlc levels as in 2009. One could argue that because of this repeated survey, the study does not longer fulfil the criteria for a cross-sectional study. However, since only 33 participants of the original GUIDANCE study filled out the questionnaires for the second time, we rather not describe our study as a longitudinal one.

\section{Comparison with existing literature}

Several studies demonstrate therapeutic inertia by identifying patients with an $\mathrm{HbAlc}>53 \mathrm{mmol} / \mathrm{mol}(>7 \%)$ and measuring the time physicians take before intensifying treatment. ${ }^{35}$ These studies show that physicians often wait months to years before initiating or intensifying T2DM therapy. This finding can indirectly be related to our results: while waiting, the patient's HbAlc will rise and thus treatment is initiated at a higher HbA1c level. Our data suggest that this level is quite often above $60 \mathrm{mmol} /$ $\operatorname{mol}(7.6 \%)$.

The little evidence that is available on physician or practice setting factors influencing $\mathrm{HbAlc}$ level at insulin initiation is inconsistent. Similar to our results, one Spanish study did not find any physician factors associated with insulin initiation at a higher HbA1c level. ${ }^{32}$ Another Korean study however, did find that physicians seeing more patients per month and female physicians waited longer before initiating or intensifying therapy. ${ }^{33}$ This study however was performed in a more homogeneous group of physicians, which might explain that significant factors were more easily found. Moreover, cultural differences might have played a role in this study too.

The differences between physicians in Europe was also found in a study on the decision to initiate antihypertensive medication. ${ }^{37}$

\section{Interpretation}

In the multivariable analysis, the only factor which was associated with initiating insulin treatment was country. In fact, country is a cultural, socio-economic and healthcare related variable. Unfortunately, we were not able to unravel whether this association was found because of differences in factors such as national guidelines, medical training or national incentives for medical care. Interestingly, no other factors were associated with the HbA1c level at which insulin would be initiated. For example, we hypothesised that physicians who provided their patients with education would have more affinity with T2DM and hence initiate insulin at either a higher or lower HbA1c level; no such associations were observed.

Furthermore, we observed higher HbA1c values in the older, complicated patient. This strongly suggests that physicians already in 2009 were individualising the glycaemic target based on patient characteristics. This is particularly interesting, because at the time of data collection of the GUIDANCE study, treatment targets were still 'one-size-fits-all' and the EASD/ADA statement proposing individualising targets had not yet been published. Physicians in our study might already have assumed that older patients would benefit less from stringent glycaemic control or were concerned about the frailty of older patients. The opposite was true for Italy, France and Belgium; physicians from these countries would initiate insulin at a slightly lower level in the older, complicated patient. Dutch physicians initiated insulin at the lowest HbAlc level compared with the other seven countries.

Studies in the past measured therapeutic inertia based on a glycaemic target of $53 \mathrm{mmol} / \mathrm{mol}(7 \%)$. In both our vignettes HbA1c values often surpass $60 \mathrm{mmol} /$ mol $(7.6 \%)$, supposedly reflecting therapeutic inertia, even present in a hypothetical situation. Individualising diabetes control according to the $\mathrm{EASD} / \mathrm{ADA}$ statement however, makes assessing therapeutic inertia more difficult. Not all patients should strive for an $\mathrm{HbAlc}<53 \mathrm{mmol} / \mathrm{mol}(<7 \%)$, so an $\mathrm{HbAlc}>53 \mathrm{mmol} /$ mol $(>7 \%)$ does not necessarily mean therapeutic inertia. We previously demonstrated that individualising HbAlc targets in T2DM patients results in more patients considered as well-controlled. ${ }^{38}$ Physicians who in the case of an older, complicated patient do not directly initiate insulin when the HbAlc level surpasses $53 \mathrm{mmol} / \mathrm{mol}$ 
(7\%), show a clinical 'inaction' rather than inertia and this inaction may be justified. If this inaction is based on the individualised approach, then it reflects a complex process of clinical reasoning, in favour of optimal patient treatment.

We found evidence that, when deciding on initiating insulin, physicians from five out of eight countries took patient's age and comorbidity status into account. Interestingly, another analysis from the GUIDANCE study, in the patient population, found evidence for overtreatment of older individuals. ${ }^{39}$ It demonstrated that the achieved HbA1c levels for individuals $<65$ years and $\geq 65$ years were similar; moreover, many of those $\geq 65$ years were treated with insulin or sulfonylureas and those with tight glycaemic control more often had ischaemic heart disease/congestive heart failure.

\section{CONCLUSION}

Our study found that the HbAlc level at which physicians initiate insulin in T2DM patients, differs between countries. This is likely to be at least partially determined by physicians' attitude towards national guidelines and may be by HbAlc targets in these guidelines. We did not identify physician or practice related factors that were independently associated with the HbA1c level at initiation. Physicians would in general initiate insulin therapy for an older patient with comorbidities at a higher HbAlc level, which reflects well considered clinical inaction rather than therapeutic inertia.

\section{Author affiliations \\ ${ }^{1}$ Julius Center for Health Sciences and Primary Care, UMC Utrecht, Utrecht, Netherlands \\ ${ }^{2}$ Faculty of Medicine, UMC Utrecht, Utrecht, Netherlands \\ ${ }^{3}$ Dept Public Health and Primary Care/LUMC-Campus The Hague, LUMC, Leiden, Netherlands \\ ${ }^{4}$ Diabetes Research Centre, University of Leicester, Leicester, UK}

Contributors EK wrote the manuscript and conducted analyses on the data. AMB designed the study. AMB, RCV and GEHMR and contributed to discussion. AMB, RCV, GEHMR and KK reviewed and edited the manuscript.

Funding The authors have not declared a specific grant for this research from any funding agency in the public, commercial or not-for-profit sectors.

Map disclaimer The depiction of boundaries on the map(s) in this article do not imply the expression of any opinion whatsoever on the part of BMJ (or any member of its group) concerning the legal status of any country, territory, jurisdiction or area or of its authorities. The map(s) are provided without any warranty of any kind, either express or implied.

Competing interests None declared.

Patient consent for publication Not required.

Provenance and peer review Not commissioned; externally peer reviewed.

Data availability statement Data may be obtained from a third party and are not publicly available.

Open access This is an open access article distributed in accordance with the Creative Commons Attribution Non Commercial (CC BY-NC 4.0) license, which permits others to distribute, remix, adapt, build upon this work non-commercially, and license their derivative works on different terms, provided the original work is properly cited, appropriate credit is given, any changes made indicated, and the use is non-commercial. See: http://creativecommons.org/licenses/by-nc/4.0/.

\section{REFERENCES}

1. Diabetes UKP, Group S. Perspectives in diabetes U.K. Prospective Diabetes Study 16 Overview of 6 Years' Therapy of Type II Diabetes. A Progressive Disease 1998:1249-58.

2. de Sonnaville JJ, Snoek FJ, Colly LP, et al. Well-Being and symptoms in relation to insulin therapy in type 2 diabetes. Diabetes Care 1998;21:919-24.

3. Holman RR, Paul SK, Bethel MA, et al. 10-Year follow-up of intensive glucose control in type 2 diabetes. $N$ Engl J Med Overseas Ed 2008;359:1577-89.

4. Ray KK, Seshasai SRK, Wijesuriya S, et al. Effect of intensive control of glucose on cardiovascular outcomes and death in patients with diabetes mellitus: a meta-analysis of randomised controlled trials. The Lancet 2009;373:1765-72.

5. Brown JB, Nichols GA. Slow response to loss of glycemic control in type 2 diabetes mellitus. Am J Manag Care 2003;9:213-7.

6. Nichols GA, Koo YH, Shah SN. Delay of insulin addition to oral combination therapy despite inadequate glycemic control: delay of insulin therapy. J Gen Intern Med 2007;22:453-8.

7. Costi M, Dilla T, Reviriego J, et al. Clinical characteristics of patients with type 2 diabetes mellitus at the time of insulin initiation: INSTIGATE observational study in Spain. Acta Diabetol 2010;47:169-75.

8. Khunti K, Damci T, Meneghini L, et al. Study of once daily Levemir (SOLVE ${ }^{\mathrm{TM}}$ ): insights into the timing of insulin initiation in people with poorly controlled type 2 diabetes in routine clinical practice. Diabetes Obes Metab 2012;14:654-61.

9. Khunti K, Wolden ML, Thorsted BL, et al. Clinical inertia in people with type 2 diabetes: a retrospective cohort study of more than 80,000 people. Diabetes Care 2013;36:3411-7.

10. Khunti K, Kosiborod M, Ray KK. Legacy benefits of blood glucose, blood pressure and lipid control in individuals with diabetes and cardiovascular disease: time to overcome multifactorial therapeutic inertia? Diabetes Obes Metab 2018;20:1337-41.

11. Pantalone KM, Misra-Hebert AD, Hobbs TM, et al. Clinical inertia in type 2 diabetes management: evidence from a large, real-world data set. Diabetes Care 2018;41:e113-4.

12. Phillips LS, Branch WT, Cook CB, et al. Clinical inertia. Ann Intern Med 2001;135:825-34.

13. Khunti K, Davies MJ. Clinical inertia-Time to reappraise the terminology? Prim Care Diabetes 2017;11:105-6.

14. O'Connor PJ, Sperl-Hillen JM, Johnson PE, et al. Clinical inertia and outpatient medical errors. Advances in Patient Safety 2005;2:293-308.

15. Haque M, Navsa M, Emerson SH, et al. Barriers to initiating insulin therapy in patients with type 2 diabetes mellitus in public-sector primary health care centres in Cape town. Journal of Endocrinology, Metabolism and Diabetes of South Africa 2005;10:94-9.

16. Ross SA. Breaking down patient and physician barriers to optimize glycemic control in type 2 diabetes. Am J Med 2013;126(9 Suppl 1):S38-S48.

17. National Institute for Health and Care Excellence. Type 2 diabetes in adults: management (NG28), 2015.

18. Information från läkemedelsverket. Läkemedelsbehandling för glukoskontroll Vid typ 2-diabetes - behandlingsrekommendation, 2017.

19. Stone MA, Charpentier G, Doggen K, et al. Quality of care of people with type 2 diabetes in eight European countries: findings from the Guideline adherence to enhance care (guidance) study. Diabetes Care 2013;36:2628-38.

20. Inzucchi SE, Bergenstal RM, Buse JB, et al. Management of hyperglycemia in type 2 diabetes: a patient-centered approach: position statement of the American diabetes association (ADA) and the European association for the study of diabetes (EASD). Diabetes Care 2012;35:1364-79.

21. Patel A, MacMahon S, Chalmers J, et al. Intensive blood glucose control and vascular outcomes in patients with type 2 diabetes. $N$ Engl J Med 2008;358:2560-72.

22. Duckworth W, Abraira C, Moritz T, et al. Glucose control and vascular complications in veterans with type 2 diabetes. $N$ Engl J Med 2009;360:129-39.

23. Gerstein HC, Miller ME, Byington RP, et al. Effects of intensive glucose lowering in type 2 diabetes. $N$ Engl $\mathrm{J}$ Med 2008;358:2545-59.

24. Polonsky WH, Fisher L, Guzman S, et al. Psychological insulin resistance in patients with type 2 diabetes: the scope of the problem. Diabetes Care 2005;28:2543-5.

25. Larkin ME, Capasso VA, Chen C-L, et al. Measuring psychological insulin resistance: barriers to insulin use. Diabetes Educ 2008;34:511-7. 
26. Peyrot M, Rubin RR, Lauritzen T, et al. Resistance to insulin therapy among patients and providers: results of the cross-national diabetes attitudes, wishes, and needs (dawn) study. Diabetes Care 2005;28:2673-9.

27. Kunt T, Snoek FJ. Barriers to insulin initiation and intensification and how to overcome them. Int J Clin Pract 2009;63(1 Suppl.):6-10.

28. O'Connor PJ. Overcome clinical inertia to control systolic blood pressure. Arch Intern Med 2003;163:2677-8.

29. Russell-Jones D, Pouwer F, Khunti K. Identification of barriers to insulin therapy and approaches to overcoming them. Diabetes Obes Metab 2018;20:488-96.

30. Khunti K, Millar-Jones D. Clinical inertia to insulin initiation and intensification in the UK: a focused literature review. Prim Care Diabetes 2017;11:3-12.

31. Shah BR, Hux JE, Laupacis A, et al. Clinical inertia in response to inadequate glycemic control: do specialists differ from primary care physicians? Diabetes Care 2005;28:600-6.

32. Olveira G, Soriguer F, Ortega C, et al. [Factors influencing the prescription of insulin and oral antidiabetics in primary care]. Aten Primaria 1999;23:260-7.

33. Kim SG, Kim NH, Ku BJ, et al. Delay of insulin initiation in patients with type 2 diabetes mellitus inadequately controlled with oral hypoglycemic agents (analysis of patient- and physician-related factors): a prospective observational DIPP-FACTOR study in Korea. $J$ Diabetes Investig 2017;8:346-53.

34. Stone MA, Wilkinson JC, Charpentier G, et al. Evaluation and comparison of guidelines for the management of people with type 2 diabetes from eight European countries. Diabetes Res Clin Pract 2010;87:252-60.

35. Mata-Cases M, Benito-Badorrey B, Roura-Olmeda P, et al. Clinical inertia in the treatment of hyperglycemia in type 2 diabetes patients in primary care. Curr Med Res Opin 2013;29:1495-502.

36. Marrett $\mathrm{E}$, Zhang Q, Kanitscheider $\mathrm{C}$, et al. Physician reasons for nonpharmacologic treatment of hyperglycemia in older patients newly diagnosed with type 2 diabetes mellitus. Diabetes Therapy 2012;3:1-12.

37. Streit S, Verschoor M, Rodondi N, et al. Variation in GP decisions on antihypertensive treatment in oldest-old and frail individuals across 29 countries. BMC Geriatr 2017;17:1-7.

38. Boels AM, Hart HE, Rutten GE, et al. Personalised treatment targets in type 2 diabetes patients: the Dutch approach. Prim Care Diabetes 2017;11:71-7.

39. Müller N, Khunti K, Kuss O, et al. Is there evidence of potential overtreatment of glycaemia in elderly people with type 2 diabetes? data from the guidance study. Acta Diabetol 2017;54:209-14. 